\title{
UM OLHAR FOUCAULTIANO SOBRE A PRODUÇÃO DE DISCURSOS NA CONSTRUÇÃO DO CORPO HETERONORMATIVO
}

\author{
Herlan José da Silva Smith ${ }^{1}$ \\ Rachel de Oliveira Abreu ${ }^{2}$
}

\begin{abstract}
Resumo:Este artigo pretende realizar uma aproximação teórica entre os estudos de Foucault sobre a produção de discursos e o debate sobre heteronormatividade, mais precisamente, refletindo sobre a produção de discursos na construção do corpo heteronormativo via mecanismos de regulação e exclusão internos a uma ordem discursiva, objetivando imprimir um suposto olhar Foucaultiano nas nuances desse fenômeno que regula os corpos, questionando também, como a forma de operar a ciência e o papel do intelectual podem ressignificar um saber que domina.
\end{abstract}

Palavras-chave:Heteronormatividade. Corpo. Discurso. Foucault. Ciência.

\section{A FOUCAULTIAN LOOK ABOUT THE PRODUCTION OF DISCOURSES IN THE CONSTRUCTION OF HETERONORMATIVE BODY}

\begin{abstract}
This article aims to make a theoretical approximation between the studies of Michel Foucault on the production of speeches and the contemporary debate on heteronormativity, more precisely, reflecting on the production of discourses in the construction of heteronormative body via regulatory mechanisms of exclusion internal to a order discursive, aiming print out an Foucauldian look the nuances of this "contemporary" phenomenon that regulates the bodies, questioning too, such as how to operate the science and the role of the intellectual can reframe an knowledge that dominates.
\end{abstract}

Keywords:Heteronormativity. Body. Discourse. Foucault. Science.

\footnotetext{
${ }^{1}$ Graduando de Bacharelado em Serviço Social pela Universidade da Amazônia (UNAMA); Graduando em Licenciatura em Pedagogia pela Universidade Federal do Pará (UFPA). Endereço eletrônico: herlansmith @gmail.com

2 Socióloga, Antropóloga, Docente da Universidade da Amazônia (UNAMA). Doutoranda pelo Programa de Pós Graduação em Sociologia e Antropologia - PPGSA da Universidade Federal do Pará (UFPA). Endereço eletrônico: rachelufpa@gmail.com.
} 


\title{
Debate introdutório sobre a noção de discurso em Foucault
}

\author{
"Mas, o que há, enfim, de tão perigoso no fato de as pessoas \\ falarem e de seus discursos proliferarem \\ indefinidamente? Onde, afinal, está o perigo?"
}

As palavras proferidas acima ondensam uma inquietação de Michel Foucault, em sua aula inaugural no College de France, no ano de 1970, sobre os rumos e a proporção de um mero jogo de palavras que, uma vez proferidas, podem tomar. Tentando desvendar as práticas discursivas e os saberes que as permeiam, Foucault expõe pormenorizadamente suas principais reflexões acerca e como os mais diversificados discursos que permeiam as diferentes sociedades podem contribuir para o controle, limitação e criação de regras, costurando nesse sentido relações de poder. Mas de antemão em que consiste o discurso? Qual seu conceito segundo a noção foucaultiana? Quais mecanismos o acompanham?

De acordo com o pensamento de Prado, Michel Foucault passa a definir o discurso como "[...] um conjunto estratégico de enunciados, com regularidades, que articula saber e poder e opera formando objetos e sujeitos. As práticas de poder não existem separadas da formação de saberes articulam-se a enunciados, geram saber, como saber gera poder." (PRADO, 1995, p. 20-21). Com efeito, o discurso pode ser entendido como um sistema complexo de enunciados que se conectam, se interligam, se comunicam com outros sistemas e que acabam não resultando os valores condensados no próprio discurso, mas que findam na constituição de poder e saber, possibilitando a emergência do binário sujeito x objeto.

Procurando desvendar a existência do discurso em Foucault e tentando conceituá-lo enquanto prática social, Cordeiro (1995) pensa a emergência dos enunciados através de um suposto método equacional enquanto resultado da relação entre linguagem e "outra coisa". Para o autor, o discurso como prática seria:

[...] essa instância da linguagem em que a língua está relacionada com "outra coisa", a qual não é linguística. Donde, a relação da língua com "outra coisa" que não é de 
natureza linguística, relação que se dá no uso da linguagem, essa relação é o discurso. O discurso é uma prática que relaciona a língua com “outra coisa”, é aquilo a que Foucault chama "prática discursiva” (CORDEIRO, 1995, p. 2).

“Na acepção tradicional, o discurso não é uma simples sequência de palavras, mas um modo de pensamento que se opõe à intuição" (AZEVEDO, 2013, p. 155). Diante do exposto, compreende-se que o discurso não é simplesmente o aparelhamento de palavras que pretendem surtir um significado próprio, mas um mecanismo estratégico que representa a ordem nas estruturas do imaginário social.

O discurso, na mais didática das explicações, pode ser caracterizado como toda e qualquer manifestação que produz sentido, mas não necessariamente o sentido elaborado em si - podendo ser representado de diversas formas - é todo "movimento" que causa algum sentido à sociedade e é “[...] organizado com o objetivo de exercer um poder através de uma ordem "verdadeira" que estabelece quais os saberes a serem preservados e quais devem ser abolidos" (RODRIGUES, 2003, p. 114).

O discurso a partir da noção Foucaultiana também pode ser compreendido como "um conjunto de regras anônimas, históricas sempre determinadas no tempo espaço, que definiram em uma dada época, e para uma área social, econômica, geográfica, ou linguística dada, as condições de exercício da função enunciativa." (AZEVEDO, 2013 apud FOUCAULT, 1960, p. 43). De acordo com esse raciocínio práticas discursivas tomam corpo no seio das instituições sociais, tendo em vista que a "aplicação e produção destes, nas instituições e nas relações sociais, definem um tipo de saber, além de determinar funções e formas de comportamento numa época" (AZEVEDO, 2013)

\section{Dos mecanismos de exclusão}

Partindo do pressuposto de que se vivencia uma sociedade, onde toda produção do discurso é simultaneamente feita de forma "controlada, selecionada, organizada e redistribuída", Foucault em a "Ordem do discurso", 
expõe que, a função desses procedimentos consiste em "conjurar seus poderes e perigos, dominar seu acontecimento aleatório, esquivar sua pesada e temível materialidade" (FOUCAULT, 1996, p. 9). De efeito, compreende-se que não há como indissociar um discurso ao poder, pois o último o controla. As falas não ecoam absolutamente livres, desprendidas, principalmente quando se vive em uma sociedade com inúmeros mecanismos de exclusão. Os próprios discursos carregam tais mecanismos consigo e foi tentando desenhar tais mecanismos que, Foucault examinara e problematizara os procedimentos que compõem o bojo dos discursos - os primeiros destes são os que passaram a ser denominados enquanto mecanismos de exclusão.

Para Foucault,

O mais evidente, o mais familiar também, é a interdição. Sabe-se bem que não se tem o direito de dizer tudo, que não se pode falar de tudo em qualquer circunstância, que qualquer um, enfim, não pode falar de qualquer coisa. Tabu do objeto, ritual da circunstância, direito privilegiado ou exclusivo do sujeito que fala (FOUCAULT, 1996, p. 9).

Diante disso, entende-se que a categoria "interdição" para o autor, compõe dentro da produção dos discursos a maneira pelo qual ele também pode ser excludente a outrem e exclusivo e ao sujeito que fala, ao sujeito dono da fala. A interdição em suas três manifestações

[...] tabu do objeto (que não se tem o direito de dizer tudo), ritual da circunstância (que não se pode falar de tudo em qualquer circunstância), direito privilegiado ou exclusivo do sujeito que fala (que qualquer um não pode falar de qualquer coisa). [...] cruzam-se, formando uma grade complexa (GENILDA, 2004, p. 2).

De acordo com Stolz, “a interdição revela, desde já, a relação entre o discurso e o poder. Precisamente aqui, propõe Foucault a necessidade de se reconhecer em nossas sociedades os procedimentos de exclusão que levam os sujeitos à submissão e ao silêncio temeroso" (STOLZ, 170, 2008). Percebe-se então que o discurso carrega poder, resultando também no jogo binário entre fala e tabu nos mais diversos campos dentro das sociedades. 
De acordo com Foucault (1996), os meios onde mais é possivel se enxergar tal perspectiva são as regiões da sexualidade e as da política, contextos que através de sua observação, o discurso manifesta seus mais tenebrosos poderes. E com base na noção foucaultiana, por mais insípido que seja o discurso, as interdições sempre irão o atingir, revelando a ínfima relação entre poder e saber.

Nisto não há nada de espantoso, visto que o discurso como a psicanálise nos mostrou - não é simplesmente aquilo que manifesta (ou oculta) o desejo;é, também aquilo que é o objeto do desejo; e visto que - isto a história não cessa de nos ensinar - o discurso não é simplesmente aquilo que traduz as lutas ou sistemas de dominação, mas aquilo por que, pelo que se luta, o poder do qual nos queremos apoderar (FOUCAULT, 1996, p. 10).

Mas os mecanismos que permeiam o discurso não cessam por aí. De acordo com Foucault, existe outro princípio de exclusão para além do que ele denominou como interdição - há também a separação/ rejeição, como ferramentas de exclusão, ambas compondo os discursos. Para explicitar tal instrumento de exclusão, Michel Foucault pensa no binário razão/loucura e traz como exemplo a figura do louco na alta idade média. O louco, para ele, seria aquele em que seu discurso não comunga com os demais discursos "racionais", a palavra do louco não é passível a verdade, a não ser a veracidade das separações, segregações e infinitos modos de exercer um processo de exclusão que dela surgiam. As “[...] suas palavras eram consideradas nulas, portanto, despossuidas de verdades, ou, ao contrário, às vezes, se eram ouvidas, eram-lhe atribuídos estranhos poderes de predição de uma verdade escondida" (GENILDA, 2004, p. 2). Logo, entende-se que o discurso do louco não era o discurso em si, mas expunha a "razão" que nele era sucumbida e diante disto, "[...] de qualquer modo, excluída ou secretamente investida pela razão, no sentido restrito, ela não existia" (FOUCAULT, 1996, p. 11).

É importante grifar diante de tal entendimento que, a partir dos procedimentos de exclusão supracitados, o discurso se torna também um mecanismo para se entender o princípio de diversos conflitos e em muitas ocasiões, sendo o causador deles. O louco não seria o louco, se não tivessem 
embutido ao seu discurso tal condição, muito menos se não tivessem utilizado, anteriormente, um discurso que apoderado de saberes o articulou dentro de tal perspectiva e/ou se não fossem sustentadas por uma série de instituições sociais que permitiram historicamente o louco não ser o dono do discurso. Aqui cabe dizer que Foucault ao trazer o dual razão e loucura por meio da figura do louco, certamente criava pressupostos intelectivos para se entender que o discurso, assim como a materialidade por meio das classes, também "separa o joio do trigo".

Para se entender os desdobramentos do discurso em Foucault, também se faz necessário citar um de seus esforços para explicitar todo esse embaralhamento que o compõe. Descartando o binário verdadeiro e falso como um suposto terceiro sistema de exclusão e tentando situar seus entendimentos em outros patamares, Foucault (1996) enquadrou a vontade de verdade (não muito dispersa dos mecanismos citados anteriormente) também como um sistema de exclusão.

Certamente, se nos situarmos no nível de uma proposição, no interior de um discurso, a separação entre o verdadeiro e o falso não é nem arbitrária, nem modificável, nem institucional, nem violenta. Mas se nos situarmos em outra escala, se levantamos a questão de saber qual foi, qual é constantemente, através de nossos discursos, essa vontade que atravessou tantos séculos de nossa história, ou qual é, em sua forma muito geral, o tipo de separação que rege nossa vontade de saber, então é talvez algo como um sistema de exclusão (sistema histórico, institucionalmente constrangedor) que vemos desenharse (FOUCAULT, 1996, p. 14).

Do mesmo modo como os demais mecanismos de exclusão sucitados por Foucault, a vontade de verdade também foi historicamente constituída e sustentada por incontáveis instituições sociais, sendo “[...] reforçada e reconduzida por todo um compacto conjunto de práticas como a pedagogia, é claro, como o sistema dos livros, da edição, das bibliotecas, como as sociedades dos sábios de outrora, os laboratórios de hoje." (FOUCAULT, 1996, p. 17). A vontade de verdade é redistribuída, de acordo com o pensamento de Foucault, justamente através de como o saber é moldado em cada sociedade. Sustentada 
por tais suportes, a vontade de verdade acaba por exercer fortemente um poder de coerção sobre os demais discursos.

Este, apesar de ser o último sistema de exclusão destacado, não deixa de ser o menos importante, pelo contrário, reforça-se reorientando os demais mecanismos de exclusão que compõem o discurso, modificando-os, lhes dando firmamento, em contrapartida, é a que não muito se fala, mesmo sendo esta, imposta ao longo da história - Só a enxergamos pela superfície, sendo assim “[...] ignoramos, em contrapartida, a vontade de verdade, como prodigiosa maquinaria destinada a excluir todos aqueles que, ponto por ponto, em nossa história, procuram contornar essa vontade de verdade..." (FOUCAULT, 1996, p. 20).

Aqui cabe realizar um ponto final no que se refere à produção de discursos ao autor supracitado, a discussão se reproduz sem fim, é fato, mas o olhar pertencente aqui se atém somente às nuances internas que compõem tais discursos, isto é, os mecanismos de exclusão que os acompanham. Foi visto que três são esses mecanismos, cada um complementando e reafirmando o outro. Da interdição à vontade de verdade, o poder é sempre presente. Presente no sentido de destacar a palavra proibida através da interdição, de segregar a "loucura" (a partir do exemplo mencionado) e de se manifestar coercitivamente por meio da vontade de verdade.

Vale ressaltar que, desse modo, ambos os sistemas de exclusão, se apresentam como impedimentos para que alguém possa anunciar livremente seu discurso. A partir dessa perspectiva, o discurso acaba por se apresentar como uma das formas mais contundentes de dominação. Desse modo, é importante reconhecer que nenhum ato discursivo é neutro - o poder sempre os perpassa.

\section{Heteronormatividade - breves apontamentos}

Se nenhum discurso é passível de neutralidade, de acordo com a noção Foucaultiana, o que pensar, por exemplo, acerca do discurso heteronormativo? Como esse discurso se estruturou? 
Para se entender tais desdobramentos e como tal discurso se firmou como norma, Petry e Meyer (2011) apontam que é necessário compreender que isto tem uma historicidade, que está intimamente ligada a articulações específicasde poder-saber que, em um determinado tempo e espaço, passaram a legitimar o comportamento heterossexual como "normal".

De acordo com o pensamento de Mello (2012) pode-se dizer que tal história de poder-saber se inicia quando o corpo sob a égide da cultura cristã se opõe a uma dualidade com a alma, sendo separado e designado de forma inerte. O corpo seria a matéria e a alma divina. Corpo material e alma imaterial, por assim dizer. Segundo Méllo (2012), essa relação dicotômica entre "animado" e "inanimado" possibilitou que a palavra "corpus" passasse a indicar objetos materiais, ou seja, visíveis. Diante disso, os corpos passam a possuir uma suposta materialidade tão sensibilizadamente fixadora que passa a atribuí-los através do caráter natural, biológico, enquanto predeterminação circunscrita que não leva em consideração outras práticas, como se os corpos fossem universalmente compostos por uma suposta essência que os define.

Mesmo na alta idade média, já se enxergava uma tentativa de delimitar os corpos, que apesar de sofrer modificações frente aos sucessivos contextos, marcou profundamente a forma como os corpos passaram a ser impressos. Neste momento, de acordo com Méllo (2012, p. 197):

\begin{abstract}
Só havia como modelo único o corpo masculino, sem a padronização de uma determinada terminologia para a genitália feminina. A mulher não tinha um órgão sexual específico. Seu órgão sexual apenas não havia se desenvolvido adequadamente e por isso tinha se enrustido, se voltado para dentro. Galeno foi o grande representante dessa forma de atuar sobre o corpo, chamada de "modelo de sexo único".
\end{abstract}

É importante observar nesse momento, não só como historicamente o discurso heteronormativo criava precedentes para ser construído, mas como o fora - a partir de quê? - isto é, por meio de quais paradigmas se desenvolveu. Nesse caso, a partir de tentativas de cisões binárias, que mesmo não adentrando no quesito da sexualidade explicitamente, partia-se vorazmente da 
lógica do velho "jogo dos sete erros" para a padronização dos corpos, levando em conta uma perspectiva genitalizante.

Mesmo que séculos depois, com a efervescência dos chamados "novos movimentos sociais", como o movimento de mulheres e o até então denominado movimento homossexual, que buscavam, por exemplo, a reinvenção de discursos patologizantes, a superação de perspectivas biologizantes, tentando, através da politização do corpo, reverter o que passou a ser enxergado outrora, o mesmo continuou sendo reflexo dos argumentos que anteriormente o definiram, isto é, ainda carregando o peso da "idade das trevas".

A exemplo disso, de acordo com o pensamento de Louro (2000) muitos ainda interpretam que a sexualidade é algo que as pessoas possuem "naturalmente" e aceitar essa ideia, reforça a dificuldade de argumentar a respeito de sua dimensão política e social ou a respeito de seu caráter construído.

Dentro dessa lógica, o discurso da heteronormatividade se moldava paulatinamente através de tal divisão. Se tal discurso passou a definir, por meio das genitálias, as identidades desses corpos, foram construídas também sua sexualidade, de forma não totalizante, por assim dizer. Desse modo "A sexualidade dos corpos permanece na modernidade como sendo natural, predefinida por Deus ou pela natureza. Temos corpos masculinos e femininos com fins de reprodução" (MÉLLO, 2012, p. 198).

A partir do exposto, já se pode perceber que a naturalização das identidades e a sexualidade desses corpos já começa a desenhar milimetricamente um determinado modo de viver - os corpos passam a se tornar binariamente heterossexuais, mais precisamente quando são meramente articulados à reprodução ou quando é dado, por exemplo, ao corpo que carrega vagina a condição compulsória de maternagem. Essa perspectiva é tão poderosa que, mesmo não refutando a dualidade corpo- alma da idade média atribuiu a alma humana também uma essência binária, ao criar “[...] modos de ser essencialmente masculinos ou femininos" (MÉLLO, 2012, p. 198). Modos de ser que, sob uma análise Durkheiminiana, dentro de sua discusão 
acerca dos fatores de coerç̧ão social, são sustentados por instituições sociais mesmo antes de se nascer.

Todas estas atribuições aos corpos foram construídas para se chegar em um "modelo concreto" de vivência e "desde a antiguidade diversas transformações na concepção de práticas corporais vão sendo constituídas, até chegarmos aos modos de viver dos nossos dias (e noites!): um corpo diagnosticado." (MÉLLO, 2012, p. 198). Diagnosticado, biologizado e sexualmente definido, poderia complementar. Tais atribuições passaram a moldar também a forma como os indivíduos regulam suas vivências. De acordo com Méllo (2012), esta é a biopolítica empregada por Foucault, que consiste em arrancar dos corpos sua eficiência. Desse modo, pensando, à luz de tal entendimento, é possível entender que a heteronormatividade seria uma forma de arrancar a intelegibilidade dos corpos, de torná-los dóceis. Seria esta uma tipologia biopolítica de controle.

De modo sinóptico, a heteronormatividade, se configura como uma perspectiva insituida, culturalmente para problematizar e estabelecer um determinado "padrão" de sexualidade aceito que passa a regular e criar fronteiras no modo como a sociedade está organizada. De acordo com o pensamento de Miskolci (apud CHAMBERS, 2003; COHEN, 2005, p. 24), “a heteronormatividade expressa as expectativas, as demandas e as obrigações sociais que derivam do pressuposto da heterossexualidade como natural e, portanto, fundamento da sociedade". Logo, entende-se que é através do pilar da normalização e naturalização que a heteronormatividade se sustenta. É lei que paira e eis, aqui, o grande triunfo ditatório desse mecanismo - Fazer um chamado para que todos se enquandrem neste padrão imposto de forma compulsória.

\section{Mecanismos de exclusão do discurso e seus lugares na construção do corpo heteronormativo}

De acordo com as premissas de Louro (2000), é possivel entender que “[...] a sexualidade envolve rituais, linguagens, fantasias, representações, símbolos, convenções... Processos profundamente culturais e plurais. Nessa 
perspectiva, nada há de exclusivamente "natural" nesse terreno, a começar pela própria concepção de corpo, ou mesmo de natureza" (LOURO, 2000, p. 5). No entanto, como pensar os corpos que não se enquadram dentro do processo de construção do corpo heteronormativo, isto é, do corpo estimulado historicamente? Como se pensar o processo de autonomia dos corpos, se os próprios discursos são atravessados por poderes que os controlam, ou seja, se nenhum discurso é passível de neutralidade é possivel encontrar os mecanismos de exclusão que, outrora, foram suscitados por Foucalt frente ao processo de construção do corpo supracitado?

Pensando na forma como as identidades podem ser estabelecidas Louro (2000) afirma que é por meio da cultura e da história que as identidades passam a se definir, não se restringindo apenas as de cunho sexuais e/ou de gênero, mas as de raça, classe, nacionalidade, e etc. Para a autora "[...] essas múltiplas e distintas identidades constituem os sujeitos, na medida em que esses são interpelados a partir de diferentes situações, instituições ou agrupamentos sociais." (LOURO, 2000, p. 6). Entretanto, o corpo, como parte "material" que compõe as diversas identidades ainda é pensado, construído, marcado e visto a partir de representações e aspectos que o apregoam dentro de determinada fixidez, como a heteronormatividade, por exemplo.

Pensando em tal premissa, é possível compreender o lugar dos mecanismos de exclusão citados em primeiro momento, dentro do processo de composição do corpo heteronormativo. Para ilustrar o primeiro destes mecanismos, toma-se como exemplo a identidade, de forma mais precisa o seu (re)conhecimento.

Acerca do processo de autoconhecimento da identidade, Louro (2000) afirma que, ao reconhecer-se, simultaneamente, é escrita a atribuição de diferenças. Para a autors, "tudo isso implica a instituição de desigualdades, de ordenamentos, de hierarquias, e está, sem dúvida, estreitamente imbricado com as redes de poder que circulam numa sociedade." (LOURO, 2000, p. 9). Partindo dessa perspectiva, o discurso heteronormativo, por exemplo, é uma prática discursiva que sendo imposta culturalmente e articulada com instituições socias, imbrica em correlações de forças, principalmente no que se refere à construção do corpo e, sobretudo, no processo de reconhecimento do 
corpo de outrem. Ora, se tal imposição é vista sob a égide de uma tipologia "biopolítica de controle", dentro de uma perspectiva foucaultiana, o lugar do corpo que transita fora de tal norma é visto na tentativa de ser reconhecido a partir do lugar que tal imposição o sujeita, isto é, a partir da vivência heteronormativa, mesmo não sendo este o seu lugar, tendo em vista que

\begin{abstract}
O reconhecimento do "outro", daquele ou daquela que não partilha dos atributos que possuímos, é feito a partir do lugar social que ocupamos. De modo mais amplo, as sociedades realizam esses processos e, então, constróem os contornos demarcadores das fronteiras entre aqueles que representam a norma (que estão em consonância com seus padrões culturais) e aqueles que ficam fora dela, às suas margens (LOURO, 2000, p. 9).
\end{abstract}

Diante do exposto, poder-se-á dizer que os desdobramentos do processo de reconhecimento do "outro", embutidos no bojo do discurso heteronormativo, desencadeia a percepção do "outro" a partir do que se é, bem como por intermédio do que se constituem os padrões culturais, o que e possibilita a exclusão daquele que não representa o modelo imposto. Louro (2000) afirma que a norma supracitada remonta e se estabelece historicamente na figura do homem branco, heterossexual, classe média urbana e cristão. A partir desse modelo, os outros passam a ser "carimbados".

\begin{abstract}
Serão os "outros" sujeitos sociais que se tornarão "marcados", que se definirão e serão denominados a partir dessa referência. Desta forma, a mulher é representada como "o segundo sexo" e gays e lésbicas são descritos como desviantes da norma heterossexual (LOURO, 2000, p. 9).
\end{abstract}

Se situarmos essa perspectiva dentro do debate sobre o processo de ordem dos discursos, mais especificamente dentro dos mecanismos de exclusão, é possivel notar um esboço de interdição sendo desenhado, pois todo e qualquer corpo que não represente a vivência da figura supracitada será passível a não possuir um lugar de fala, sobretudo, dentro de uma sociedade onde não são tomados como referência. 
O processo de auto reconhecimento das identidades, a partir do modelo que representa a norma em questão não possibilita que o corpo do "outro" seja o dono da fala, não é à toa que historicamente os corpos que subvertem tais padrões, que não estão dentro do "modelo" estimulado, como por exemplo, os corpos das identidades do movimento LGBT, são passíveis a submissões, são tomados como abjetos, pois dentro desse jogo do processo de reconhecimento das identidades, as suas estarão sempre do outro lado dos “[...] contornos demarcadores daqueles que representam a norma" (LOURO, 2000, p. 9). Nesse sentido, quando se cria tal dicotomia através do corpo, não poderá o "anormal" falar, consequentemente, a interdição o atingirá, seja qual for o discurso, pois “[... ] a esses restam poucas alternativas: o silêncio, a dissimulação ou a segregação" (LOURO, 2000, p. 18).

Michel Foucault (1999), no primeiro volume de "História da Sexualidade", tentando demarcar as fronteiras estabelecidas através de uma suposta "crônica da repressão" mostra que as sexualidades não reconhecidas, expressas nos corpos que persistem no "estéril", são tomadas como "anormais" e ao receberem este status, pagam sanções. Nesse sentido, para o autor "o que não é regulado para a geração ou por ela transfigurado não possui eira, nem beira, nem lei. Nem verbo também. É ao mesmo tempo expulso, negado e reduzido ao silêncio." (FOUCAULT, 1999, p. 10).

Desta forma, ao criar tal demarcação entre os corpos que se enquadram dentro da norma e os que dela não comungam, Louro passa a afirmar que "ao classificar os sujeitos, toda sociedade estabelece divisões e atribui rótulos que pretendem fixar as identidades. Ela define, separa e, de formas sutis ou violentas, também distingue e discrimina." (LOURO, 2000, p. 9). Isso nos conduz ao segundo ponto desta discussão - pois dentro do processo de classificação dos sujeitos se desarma outro princípio de exclusão que compõe o discurso, a partir das formulações de Michel Foucault, a Sepração/Rejeição, pois se situarmos essa necessidade de classificação dos sujeitos no cerne do debate sobre representação das identidades, não teremos, é claro, a oposição razão e loucura, como Foucault exemplificou anteriormente, mas o binário de distintas representações identitárias que se cruzam 
[...] travam batalhas decisivas de criação e imposição de significados particulares: esse é um campo atravessado por relações de poder [...] o poder define a forma como se processa a representação; a representação, por sua vez, tem efeitos específicos, ligados, sobretudo, à produção de identidades culturais e sociais [...] (SILVA 1998 apud LOURO, 2000, p. 9).

A representação tem efeitos colaterais específicos e contundentes, pois “[...] aprendemos a classificar os sujeitos pelas formas como eles se apresentam corporalmente, pelos comportamentos e gestos que empregam e pelas várias formas com que se expressam." (LOURO, 2000, p. 9). De acordo com Louro (2000), as diversas e distintas representações, podem, reproduzir efeitos sociais e alguns desses “[...] ganham uma visibilidade e uma força tão grandes que deixam de ser percebidas como representações e são tomadas como sendo a realidade" (LOURO, 2000, p. 9).

O que seria a lesbo, homo, bi, trans - fobia, se não efeitos sociais avassaladores de classsificação dos sujeitos pelas formas como expressam seus corpos por meio das sexualidades e identidades de gênero tidas como “desviantes"? Tomando a Transfobia como exemplo, que efeito social seria este se não uma forma contundente de separação/rejeição daqueles que não representam o modelo hegemônico de corpo? Assim como a figura do louco pensado por Foucault na alta idade média, que instituições sociais hoje empreendem forças para romper com a serapação/rejeição sob as identidades e corpos trans? Assim como a loucura fora separada e rejeitada pela razão, por meio da figura do louco nas sociedades de outrora, os corpos que não representam a hegemonia, são repelidos e violentados, não por possuírem um discurso que rompe a racionalidade, mas por carregarem no corpo a marca da transgressão. Esse suposto "carimbo subversivo" é empreendido na maioria das vezes por ações tirânicas de violência e dominação, assim "gradativamente, vai se tornando visível e perceptível a afirmação das identidades historicamente subjugadas em nossa sociedade" (LOURO, 2000, p. 21).

Nesse sentido, "os grupos sociais que ocupam as posições centrais, "normais" (de gênero, de sexualidade, de raça, de classe, de religião etc) têm possibilidade não apenas de representar a si mesmos, mas também de 
representar os outros. Eles falam por si e também falam pelos "outros" (e sobre os outros) [...]" (LOURO, 2000, p. 9). Foi tentanto falar pelos "outros" que ao longo da história os supostos corpos "subversivos" foram tomados pelas identidades que ocupam as posições hegemônicas como sendo doentes, criminosos, pecaminosos, hostis, e etc.

Essa premissa põe em cheque o terceiro mecanismo de exclusão que compõe as entranhas dos discursos, a Vontade de verdade, pois se levarmos em consideração esses empreendimentos que gradativamente tornaram visíveis o histórico de subjugação que os domina, nos deparamos com grandes teias de saberes que perpetuam normas, conceitos e definições, que tentam falar pelos "outros" e sobre "outros". Um grande exemplo desse empreendimento na história é o clássico fato da homossexualidade ter sido cunhada como patologia ao longo dos anos, corpos que carregavam essa sexualidade eram tidos como doentes. Hoje, essa história se repete com a transexualidade, que, sob o peso de diversos suportes institucionais, é enquadrada por pressupostos patologizantes, vinculados a saberes médicos, da psiquiatria e etc.

Foucault, ainda no primeiro volume de História da Sexualidade, ao questionar a crescente crônica de uma suposta repressão sobre o sexo, com a origem datada em suas hipóteses a partir do século XVII, aponta que a "circunspecção da prudência médica" e a "garantia de inocuidade científica", serve "[...] para tudo manter sem receio de transbordamento, no mais seguro e mais discreto espaço entre divã e discurso." (FOUCAULT, 1988, p. 11).

Desse modo, as formas como as identidades são representadas por essa vontade de verdade que versam os corpos são sempre atravessadas e marcadas por relações de poder. Poder estabelecido por meio da criação de um corpo hegemônico que violenta outrem, mas que no próprio ato de violentar, esboça o "fracasso ou resíduo, da história das tecnologias de normalização do corpo" (PRECIADO, 2006, p. 14). 


\section{"Ciência universal", discursos diferenciais e ressignificação do discurso científico - por um saber rasteiro}

Em entrevista publicada no livro Microfísica do Poder, Michel Foucault (1979) esboçando brevemente o percurso que o levou de seu legado sobre a loucura na idade média clássica ao estudo da criminalidade e da delinquência, destaca as nuances problemáticas que permearam as análises que realizara entre os anos de 1950-1955, pontuando, entre elas, o estatuto político da ciência e as funções ideológicas que poderiam veicular.

O problema mencionado, de acordo com Foucault (1979), não era exatamente sobre a dominância do problema "Lyssenko", mas que envolto a esse "caso escandaloso" apareciam duas questões que considerara interessantes e que poderiam ser salientadas em duas palavras resumidas poder e saber. A sua História da Loucura fora escrita dentro desse contexto, ele pontua.

Sua maior indagação girava em torno do saber científico. De acordo com Foucault, tratava-se de questionar o seguinte: “[...] se perguntarmos a uma ciência como a física teórica ou a química orgânica quais a suas relações com as estruturas políticas e econômicas da sociedade, não estaremos colocando um problema muito complicado?" (FOUCAULT, 1979, p. 1). Em contrapartida, se voltássemos essa mesma pergunta a uma ciência como a psiquiatria, será uma questão muito mais fácil de ser resolvida segundo o autor, uma vez que, de acordo com a sua linha de raciocínio, o perfil epistemológico da psiquiatria é pouco definido e por que a sua prática está ligada a uma série de instituições, imediatas exigências econômicas, de urgências políticas e de regulamentações sociais. Tomando este ramo do conhecimento enquanto "ciência duvidosa", o autor questiona se através dela, bem como por meio da medicina, não poderíamos apreender de forma mais precisa o entrelaçamento dos efeitos de poder e de saber.

Deixando a psiquiatria de lado e tomando como pressuposto o que já fora discutido aqui, tomam-se essas premissas acima para se considerar o seguinte: até que ponto problematizar o discurso heteronormativo, refletido enquanto síntese de um discurso científico põe em xeque a própria ciência universal? Esse questionamento conduz a um caminho bifurcado: se vista 
através de um olhar macro, questionar a construção do corpo heteronormativo dentro de um ponto de vista considerado "científico", seria reafirmar de certo modo, binarismos e consequentemente, a existência desse próprio corpo. Fato. Haja vista, porque há de se reconhecer justamente a importância desse “entrelaçamento" entre poder e saber no qual Foucault (1979) propõe.

Ora, se vimos aqui, que pensar acerca da "história" do "corpo heteronormativo" é deparar-se com construções de saberes sobre o próprio corpo, como os empreendimentos do discurso científico (a exemplo: o modelo de sexo único), que sucedeu os enunciados religiosos sobre o corpo na idade média, é importante destacar uma questão preponderante para se pensar a respeito do questionado acima: segundo as premissas de Foucault (2010), não há saber que simultaneamente não suponha ou não constitua relações de poder e não existe relação de poder sem constituição correlata de um campo de saber, isto é, saber gera poder.

Nesse sentido, não há como discutir a (des)construção da problemática aqui travada, se não tomarmos como ponto de partida o próprio discurso científico, uma vez que, segundo as premissas de Adinolf (2007), o discurso científico é essencial para a própria ciência, justamente porque romper com opiniões, com o imediatismo, com a ordem do real, com a universalidade e buscar objetividade faz parte da construção da própria ciência e da sua diferença entre os variados saberes, dentre eles o senso comum.

Dessa forma, problematizar o que é derivante de um saber científico discursivo universal, dentro dessa lógica, pressupõe partir do próprio discurso científico, não só para contestar o que historicamente fora produzido a partir de uma ciência universal, mas para apontar que existem saberes diferentes, saberes rasteiros, que atestam não só equívocos na história que tratou esse corpo como hegemônico, único e incontestável, mas para aduzir as fragilidades da própria ciência.

Em contrapartida, ao se pensar acerca dessa questão por meio de um viés micro, proponho pensar o seguinte: contestar as formas de hegemônia dentro da produção de saberes é operar fortemente contra um discurso científico universalizante. O que não significa negar a ciência em si, muito menos a existência desse corpo em outrem ou em si, quiçá para aludir à 
existência de um saber politizado, ressignificado e menos heterocentrado dentro daquilo em que se conhece tanto por ciência quanto por corpo. É desta forma que se colocam em xeque não só as nuances de uma problemática derivada de um saber científico, mas a própria maneira de se discutir ciência operando num sentido de transformação - discursiva.

O problema aqui travado não foi exatamente só o de dizer: viva a pluralidade de corpos, de manifestação dos gêneros e das sexualidades, mas de colocar o seguinte: ordens de saber operam num sentido de perpetuar ideologias e normatizações e que este esforço deve ser rompido em suas próprias raízes, por ser uma delas, dentro da própria ciência. Um grande exemplo dessa hipótese na atualidade é que, de acordo com a Classificação Estatística Internacional de Doenças - CID 10, publicação da Organização Mundial da Saúde - OMS, a transexualidade, lá terminada pelo sufixo "ismo", é tida na categoria F-64 - de "transtornos da identidade sexual", mantida no grupo F-60/69 como "transtorno da personalidade e do comportamento do adulto" e catalogada em seu capítulo $\mathrm{V}$, na qualidade de "transtornos mentais e comportamentais". O corpo trans ainda é tido como patológico e sua "enfermidade" é sustentada por um conjunto compacto de instituições, regulamentações e de saberes científicos que atuam produzindo o que somos ou que deveríamos ser, ilustrando uma característica do primeiro mecanismo de exclusão do discurso apontado por Foucault (1996) e mais do que isso, registrando os efeitos da dicotômica relação entre poder x saber em tons de transfobia científica.

Uma questão preponderante para se pensar acerca do discutido até aqui, parafraseando Foucault (1979), é refletir sobre a modificação das regras de formação dos enunciados que são aceitos como cientificamente verdadeiros, não negando a ciência, mas tendo o entendimento de fazer uma reflexão a respeito dos seguintes questionamentos: o que rege os discursos científicos? Como estes são regidos? A quem interessam e o que produzem? Ao sustentar um conjunto de proposições científicas normativas ao corpo - como a heteronormatividade, - é demasiado perceptível apontar o quê em nome da ciência universal - ou a própria - exclui e o que produz: corpos marginalizados via ditadura heteronormativa. 
Neste caso, “[...] não se trata de saber qual é o poder que age do exterior sobre a ciência, mas que efeitos de poder circulam entre os enunciados científicos; qual é o seu regime interior de poder; como e por que em certos momentos ele se modifica de forma global." (Foucault, 1979, p. 1). Essa afirmação conduz a um caminho final a ser refletido aqui: qual é o papel do intelectual nesse processo?

Foucault (1979) destaca que um dos papéis do intelectual durante a história era o de dizer a verdade para aqueles que ainda não a podiam enxergar e em nome daqueles que não podiam pronunciá-la, no entanto, seu papel hoje, se estabelece na contramão desse esforço. Para o autor, os intelectuais se atentaram para a necessidade recente de que as massas não carecem deles para "saber". Foucault afirma que as grandes massas detêm o saber perfeitamente e em muitas ocasiões, muito melhor do que os intelectuais e elas podem manuseá-lo muito bem. Contudo, de acordo com o pensamento do autor, existe um sistema de poder que barra, que proíbe, que invalida o discurso e o saber das massas.

A respeito desse poder, Foucault (1979) diz que não se encontra de forma exata nas instâncias superiores da censura, mas que penetra de forma tão eficaz em toda a trama da sociedade. O autor não problematiza essa estrutura, não a nomeia, mas convida a pensar sobre o seguinte: os intelectuais são pertencentes a esse sistema de poder, bem como o pensamento que diz que eles são os promotores da "consciência" e do discurso. Nessa perspectiva, o papel do intelectual não é o de inverter os papéis com a massa, não é o de se colocar "um pouco na frente ou um pouco de lado para dizer a muda verdade de todos; é antes o de lutar contra as formas de poder exatamente onde ele é, ao mesmo tempo, o objeto e o instrumento: na ordem do saber, da 'verdade', da 'consciência', do discurso" (FOUCAULT, 1979).

Partindo dessas premissas e levando em conta a discussão aqui travada, ao refletir sobre a produção de discursos na construção do corpo heteronormativo, via mecanismos de regulação e exclusão internos a uma ordem discursiva, não se estaria exatamente pondo em questão uma imagem científica de discurso, de subjetividades e de um corpo heteronormativo, mas a função do próprio intelectual enquanto mantenedor ou reprodutor dessa 
lógica. Dessa maneira, contestar a problemática aqui tratada e questionar a maneira como a ciência a sustentou/sustenta, é promover o que o espírito foucaultiano nos convida a exercitar: politizar o conhecimento, a ciência, o saber e utilizá-los como ferramenta em prol das lutas de grupos “minoritários".

\section{Considerações finais}

Este trabalho logrou refletir acerca de uma problemática cadente - a heterormatividade - especialmente no que se refere às implicações da construção do corpo heteronormativo nos demais corpos - associando-a ao debate sobre a produção dos discursos em Foucault, de caráter mais específico, acerca dos mecanismos internos que compõem os discursos, segundo as hipóteses foucaultianas. Em primeiro momento, foi permitido esclarecer que $o$ discurso não é simplesmente o acúmulo de palavras que carregam sentidos aleatórios em sí, mas um mecanismo estratégico de dominação e de controle, caracterizado por três "ingredientes" que lhes acompanham internamente - a interdição, a separação/rejeição a vontade de verdade-ingredientes que dão sabor dualístico às práticas discursivas - sabor dual expresso no fato desses mecanismos emanarem sentidos sigulares e comuns. Singulares por produzirem efeitos específicos cada um, mas comuns quando são observados por meio de um olhar macro que os define - a interdição cala, a separação segrega e a vontade de verdade domina - mas ambos promovem e são o que Foucault denominara - exclusão, esse efeito os assemelha e faz das práticas discursivas, campos de concentração minados de relações de poder. A região da sexualidade, como Foucault explicou em "A ordem dos discursos" faz juízo a esse entendimento.

Tomando essas premissas como valor, partimos para o segundo momento, tentando compreender os desdobramentos da heteronormatividade, procurando entender como esse discurso se firmou ao longo dos tempos e como é entendido enquanto um "chamado obrigatório". Posteriormente, se tentou estabelecer uma conexão dos mecanismos internos citados anteriormente dentro do processo de construção do corpo heteronormativo como uma espécie de diálogo dos debates anteriores. Para isso, associou-se a interdição ao processo de representação das identidades, a 
separação/rejeição dentro do debate sobre o processo de classificação dos sujeitos e, por fim, menciona-se a vontade de verdade vinculada ao saberes referentes à homossexualidade e transexualidade, como verdades e saberes que, respectivamente, patologizaram/patologizam, que dominam e violentam, enquanto exemplos que ilustram consequências materializadas e concretas de relações de poder que versam os corpos, sustentadas por práticas discursivas recheadas de relações de poder, poder presente na forma quando se destaca a palavra proibida e o silêncio, quando se perpetua a segregação e, principalmente, quando os saberes que atravessam nossos corpos passam a moldar aquilo que "somos" ou aquilo que devemos "ser". Por fim, se tentou relfetir a respeito da necessidade de construir uma ciência rasteira que não opere num sentido de dominação, mas que seja utilizada como ferramenta em prol das lutas de grupos marginalizados, politizando o conhecimento, o saber e o discurso.

\section{Referências}

ADINOLFI, Valéria Trigueiro Santos. Discurso científico, poder e verdade. In: RAGO, M.; MARTINS, A. L. Dossiê Foucault, n. 3, dez. 2006/mar. 2007. Disponível

em: http://www.ifch.unicamp.br/ojs/index.php/aulas/article/download/1940/14 01 Acesso em: 05 ago. 2016.

AZEVEDO, Sara Dionizia Rodrigues de. Formação discursiva e discurso em Foucault. São Paulo: ISSN 1984-1159, v. 6, n. 2, 2013. Disponível em www.marilia.unesp.br/filogenese. Acesso em: 01 nov. 2015.

CORDEIRO, Edmundo. Foucault e a existência do discurso. Cadernos do Noroeste. Universidade do Minho, Braga, v. 8 (1), 1995, p. 179-186.

OMS. Classificação internacional de doenças - CID10. Busca por códigos. Transexualismo. Disponível em: http://www.cid10.com. br/buscacode?query=F64 2013. Acesso em: 05 ago. 2016. FOUCAULT, Michel. A ordem do discurso. São Paulo: Loyola, 1996.

FOUCAULT, Michel. História da sexualidade. Rio de Janeiro: Graal, 1988. 
FOUCAULT, Michel. Vigiar e Punir: nascimento da prisão. Petrópolis: Vozes, 2010.

FOUCAULT, Michel. Microfísica do Poder. Rio de Janeiro: Graal, 1979.

GENILDA, D'Arc Bernardes. Resenha de: A ordem do discurso de Michel Foucault. Sociedade e Cultura. Jul-dez, v. 7, n. 2. Goiânia: Universidade Federal de Goiás, 2004, p. 247-250.

LOURO, Guaracira Lopes. Pedagogias da Sexualidade. In: LOURO, Guacira Lopes (Org.). O corpo educado - pedagogias da sexualidade. Belo Horizonte: Autêntica, 2000, p. 7-34.

MÉLLO, R. P. Corpos, heteronormatividade e performances híbridas. Psicologia \& Sociedade, 24(1), 2012, p. 197-207.

MISKOLCI, Richard. A teoria queer e a sociologia: o desafio de uma analítica da normalização. Sociologias. Porto Alegre, ano 11, n. 21, jan./jun. 2009, p. 150-182.

PRECIADO, Beatriz. Multidões queer: notas para uma política dos anormais, $v$. 19, n. 1. jan/abr. Florianópolis: Revista Estudos Feministas, 2011, p. 11-20.

PETRY, Analídia Rodolpho; MEYER, Dagmar Elizabeth Stermann. Transexualidade e Heteronormatividade: algumas questões para pesquisa, $v$. 10, n.1, jan./jul. Porto Alegre: Textos \& Contextos, 2011, p. 193-98. Disponível em: http://revistaseletronicas. pucrs.br/ojs/index.php/fass/article/viewFile/7375 /6434> Acesso: 01 nov. de 2015.

PRADO FILHO, Kleber. Controle social x subjetividade na genealogia do poder de Michel Foucault. n. 2, v. 1. São Paulo: Revista Plural-Sociologia, USP, 1995, p. 18-36. Disponível em: < http://www.revistas.usp.br/plural/article/view/68041/70611> Acesso: 01 nov. 2015.

RODRIGUES, Sergio Murilo. A relação entre o corpo e o poder em Michel Foucault, v. 9, n. 13. Belo Horizonte: Psicologia em Revista, jun. 2003, p. 109-124.

STOLZ, Sheila. A ordem do discurso e suas relações com o poder: vertigem e quebra de certezas. Rio Grande: JURIS, 2008, p. 159-176.

Recebido em 07 de agosto de 2016.

Aceito em 11 de outubro 2016. 